\title{
Green Manufacturing Practices in Manufacturing Industry: A State of Art
}

\author{
Mahakdeep Singh $^{1}$, Kanwarpreet Singh $^{2}$ and AmanpreetSingh ${ }^{3}$ \\ ${ }^{1}$ Department of Mechanical Engineering, Chandigarh University, Gharuan, Punjab, India \\ ${ }^{2}$ Punjabi University, Patiala, Punjab, India \\ ${ }^{3}$ BBSBEC, Fatehgarh Sahib, Punjab, India
}

\begin{abstract}
Indian Market is growing globally but with this growth the risk to human life is also increasing as the environment is getting adulterated day by day, this adulteration is due to the pollution caused by automobiles, factories and other manufacturing units. For the risk to be lightened on human race there is a need to brighten the minds of manufactures and industrialists in order to shift their manufacturing techniques from conventional to Green manufacturing techniques. Recently, concern for the environment has led manufacturing industries to take a proactive role in the development of cleaner manufacturing processes and the design of recyclable products. As the most recent update many prominent agencies like UNFCCC (United Nation Framework Convention on Climate Change) are imposing new laws for more greener environments in all over the world, so this paper focuses on the review on the research os various researchers which they have published world wide in prominent journals in adaptation of Green manufacturing techniques by Manufacturing Industries.
\end{abstract}

Keywords: Green Manufacturing (GM), Green Supply Chain Management (GSCM)

\section{INTRODUCTION}

Due to embedded Industrialization in a country, percentage of inhabitants below power has been reduced exponentially during recent times. Large gap is monitored among different nations and creating two different worlds: Privilege Group and Developing Nation. Some of nations in Asia, especial eastern part are moving rapidly to Industrialization but due to non-utilization of resources and not able to match with futuristic trends of Industrialization, some part especially Sub-Saharan Africa; population of rural inhabitants increased and largely effected its share and growth of region. Industrialization plays an important role in developing a makeable figure on sets of Global Economy. Financial and authentic research has overwhelmingly demonstrated that industrialization is connected to rising trainings, longer life ranges, developing individual and national wage, and enhanced general personal satisfaction. This all is based on the quality and techniques used for manufacturing in these Industries.

Manufacturing is the foundation of any industrialized country.Manufacturing and specialized staff in industry must know the different manufacturing techniques, materials being handled, tools and equipment for manufacturing diverse parts or items with ideal process plan. Manufacturing techniques are very important in the manufacturing environment to produce its end products for the social causes. The knowledge of manufacturing techniques is necessary for all technicians and engineers for evolving themselves with modern concepts of manufacturing practices. Competitive manufacturing time of highly modern development and research is being known as the time of automation and CIM (computer integrated manufacturing).

Because of new advances in the manufacturing field, the stage has come to this limit that each distinctive part of this technology has turned into an undeniable crucial and propelled study in itself. This has led to introduction of optimized design and manufacturing of new products. New advancements in manufacturing territories are choosing to exchange more skill to the machines for extensively decrease of physical work. There have been forceful regulatory norms by the government that forces the industries to follow the eco-friendly systems and shift the manufacturing systems to Green Manufacturing systems.

Now days, Green Manufacturing (GM) involves manufacturing of green yield or product; used for RES, nonconventional Energy sources, and a clean technology mechanism to evolve with. It also evolve with a mission to reduce polluted waste and greenhouse emissions by limiting penetration of conventional energy sources like coal and its byproducts. Futuristic Trends in Manufacturing indicates that reuses and recycles of waste products leads to new era of products which enhances the global economy at large and region in general. US remain the world's largest manufacturing economy, producing.

According to National Association of Manufacturers, around the world $48 \%$ of manufacturing products is being shared by US (21\%), China (17\%), Japan (12\%) and, the need of hour is to develop global economies and reduce carbon footprints for sustainable environment, and new technologies for new century emerging like clean mechanism and non-conventional energy sources (RES) only way to accomplish vision .A robot is a programmable machine that can perform variety of tasks depending upon the requirements and the programming. 


\section{SHIFTING OF TRADITIONAL MANUFACTURING TECHNIQUES TO GREEN MANUFACTURING}

Economy in today's world is dynamic and subjected to more demand supply relationship and success rate of organizations shows their ability to meet the level of agility for transformation according to demands. Organizations that are dynamic, improves sustainability in a competitive business environment with their shifting of traditional (conventional) manufacturing to new type of Environmental sustainability to fulfill the gap by adding to Green Manufacturing.

Industries are prone to work in a green environment and willing to be in a process of production of green products; adapt to recycling and clean mechanism for improving sustainability in order to achieve deliverables. The main objective to adapt with new green technologies to work in a suitable and growing environment and leads to production of products which are not harmful to surroundings Globally, USA, EU, Japan are leaders in implementation where as in India, measures on prevention and pollution control, new guidelines are being issued to industries by Ministry of Environment and Forest (MOEF) These norms are in accordance with ISO standards especially for Industries and Generation utilities in which by products or their outcome directly or indirectly effects environment and leads to toxic environment for inhabitants. Guidelines issues to industries need to comply by every industry otherwise MOEF will take hard action even closure of non-performing industry. Even though, court also took harsh decision in order to implement guidelines by shunting out diesel vehicles in National Capital of India, Delhi along with closing of mining work leads to a huge loss and millions jobless working in those industries, Broadly, Green Manufacturing System (GMS) has been considered as a upper hand in competitive environment in fact it has various side effects in terms of cost and decision making should be clearly monitored before switching to new technology. Personnel form Industries view GMS as a viable alternative and making their implementation easy to adapt with existing technologies. Due to lack of awareness and assessment of performance indices due to (Azzone and Noci, 1998), it becomes difficult to adapt green technologies and viable and follow the norms and guidelines to comply. The major factor underlying is the norms should be specified in a sequential manner in consideration of consumer needs and environmental protection both hand in hand to avoid any complexity and growth of economy which mostly relies on industries. (Sangwan, 2006).

\section{EVOLUTION OF GREEN MANUFACTURING}

Literature shows that various strategic issues are taken in consideration while deciding for Manufacturing, one of the reasons are Environment Protection and sustainability (Bloom and Morton, 1991;Welford and Gouldson, 1993; Clark et al., 1994;Walley and Whitehead, 1994;Welford,
1995; Azzoneet al., 1997). Globally, there is a major concern over use of natural resources and for environmental protection, although scarcities of them make managers forced to think about managing resources and diverted through Green Manufacturing. In European Countries, especially in engineering applications; certain norms are imposed on industries for environmental protection and industries pave off to reduce environmental risks and exposure to radiation with less use of plastic; keep them as on high priority along with cost effectiveness and quality indices. Even though, today Green manufacturing and Environmental protection for industries become a competitive marketing spree on different platforms (Noci, 1995). In recent development, all cars manufacturing industries gave importance to automation and considering it as a strategic decision; they all matched up and go for an alliance to make standardized design for reducing lead time and improving quality standards; a win-win situation for end consumers.

Awareness among peer groups in Utilities in Government and Private sector, pressure has been build up to reduce consumption of products which are not environment friendly and somehow possess threat to environment and possible causes to global warming in a larger way. Industries are prone to use of products which are not disposed enough but due to ever increasing demand to put a one and last stop on issue of global production of products in relevance with environmental protection; various measures have been taken to reduce pollution (especially produced by Heavy Industries). In a power station, Electrostatic Precipitators for removing an effect of flue gases which contain gases responsible of global warming and even causes tuberculosis like diseases, desulphurization also conducted enormously to reduce its effect on boiler used in power stations or industries involved in heavy manufacturing units, it has been observed that with more concentrated desulphurization; sludge formation reduced to $16 \%$ with no harmful by-products. In a recent development towards pollution control, bags made up of plastic or polythene which are not able to dispose off are banned and court also made it hard guidelines to follow the same.Industries are forced to leave "end of pipe" approaches and leaning towards "clean or green" manufacturing, which is a future of manufacturing and provides maximum utilization and efficient deliverables.

There are various concerns regarding Ecology and can be broadly classified into various classified approaches- A approach under which associations utilize natural assurance measures and consider biodegradable items, compliance approach wherein associations follow the ecological regulations. Furthermore consider ahead persistent change, lastly a framework deals with non-conventional concerns pertains to clean assembly of points way to deal by emplaning a framework. (Melnyk and Smith, 2012) characterized GM "a framework that incorporates item and procedure outline issues with issues of manufacturing planning and control in such a way as to recognize, 
measure, evaluate, and deal with the stream of environmental waste with the objective of decreasing and at last minimizing environmental impact while additionally attempting to expand asset productivity". GM is a combinational of clean technology and practices of manufacturing employing environmental protection and ecology. The main objective is to overlap the part of regions to the extent where all are bounded together to work embodied to fulfill the prominent feature of GM involving environmental impacts and green practices reducing risks of global warming and pollution. Environment is of top priority as we all whether supplier, distributor. Industries and end consumer live in an conducive region to increase productivity, however considerations should well take while designing of product and in accordance with demand and supply ratio.

GM is a continuous mechanism involving environmental indices improvement compressing of industrial processes, production of green products, no harmful by-products and operative value under clean operations. GM prefers quick operations with environmental protection with viable products, includes implementation of friendly environmental approach in the areas of production and avails accolades. This implantation is set goal for future, aims to accomplish for the betterment of society in large comprises of utilities, and inhabitants. It is as give and take process, more concentration about environmental protection; better results for manufacturing, end consumers and improves sustainability.It is termed as an efficient methodology / formulation for a problem to be accessed in terms of technology interface, safety measures and evaluation on the grounds of Environmental protection (Richards, 1994).

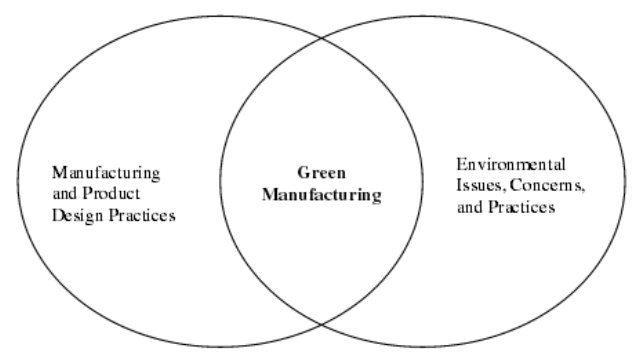

Fig. 1 Green manufacturing overlapping (Richards, 1994)

The main objective to minimize the impact of industrial processes on environment, even though, if it addresses a specific impact in one of the subset of environment, then it must be ensured that its viability must be checked for a large system not for a specific Industry. For example, if utilities are reducing flue gases discharge, the entity is involved in reducing pollution but must be ensured in whole to reduce the environmental pollution in large and benefit a society. GM is not a single term and it envelopes a range of technologies varying from clean, conscious, responsible and sustainable manufacturing, although all terms are relation with environment and access impact on environment by industrial process and reduces its bad effect to serve the society in a modeled way. It involves design and improves deliverables which decide the designingand delivering products that minimize negative effects on the environment throughtheir production, use, and disposalas shown in Figure. 1.

\section{LITERATURE REVIEW}

Business associations have been utilizing different assets to effectively take care of the demand-supply comparison at the commercial center. $\mathrm{Be}$ that as it may, today organizations and consumers have understood the greatest outcome and test going up against them is the need to secure and safeguard the natural resources and their production and utilization conduct can straightway affect the Ecological balance of nature (Ganet al., 2008). The decay procedure of natural resources caused by such exercises call for responsible roles to be accepted by all included, the customer, governments, institutions, associations and the media, in order to meet the natural crisis(Carreteet al., 2012). Passing by this are the current famous buzz proclamations: usage of sustainable energy, consume green products, focus on green marketing practices etc, this social concern and obligation towards improving manageability has prompted the development of advertising systems that advance this and green promoting is one such field.

Authors (Digalwaret al., 2016) discussed performance indices of GM when implemented with manufacturing industry with an objective to improve sustainability in terms of environmental protection and reduce pollution. It has been observed that by author that cost effectiveness and risks has been considerable reduced while adopting decisive strategic approach in accordance with end consumer requirement and growth of industry. It has also been depicted that only implementation of model of GM not helps in specific industry but identification of critical parameters which effect the performance indices (can vary) should be understood and evaluated by researchers and managers collectively before implementation to a system for better results. Some tested theories also applied for heavy industries.

Apart from social responsibility of the organizations there has been the regulatory norms by the government which force the organizations to implement Green Operations in their firms. (Mathiyazhaganet al., 2014) found the bounding forces that force the organizations to implement green manufacturing operations from his questionnaire based survey from different industrial sectors

Internationally research has been done and discussed globally about the green manufacturing operations to be adopted by the organizations. Practitioners (Nunes and Bennett, 2016) observed that automation is also a part of GM as certain operations which are not environment friendly; can be automated and therefore operations apart from green practices fulfill the objective of making environment free of pollution and friendly with industry operations. It has also been depicted that leaders in 
automobile manufacturing specially four vehicles taking initiative in bringing innovation and green practices for supply chain arrangement, eco friendly buildings with limited use of ventilation and cooling with external machines, reducing negative impact on environment along with inverse logistics. This all will help in GM whether it falls into a category of manufacturing or not but fulfill broader and sole objective of environmental protection.

Researchers (Gupta and Ogden, 2009; Singh and Bansal, 2012) found that consumers had awareness, concern and positive inclination towards green products but were hesitant to purchase it owing to the higher prices involved. This positive attitude yet hesitant purchase behavior is puzzling marketers.

The researchers (Nair and Maram, 2015) examined the potential of green consumer behavior mainly focused on how this could contribute towards Sustainable development. They proposed a simple framework calling for the coordinated efforts of all involved to work towards sustainable development of green consumer behavior.

Some of the researchers like ( Kumar et al., 2015; Srivastav and Gaur, 2015) have found the barriers in implementing green Operations in the Indian Manufacturing firms, these barriers include many dependent and independent variables like lack of acceptance of advancements, lack of skilled labor, poor organization culture etc. They structured a model to appreciate interdependence of the barriers.

\section{RESEARCH GAPS IN LITERATURE REVIEW AND NEED FOR PRESENT STUDY}

A vast literature is available and lot of Researcher's theories and discussions are available on GM taken in consideration of various performance indices and various parameters like economic variability, competitive market and cost productiveness. There are lot of theories and research available in implementation of GM in industries and barriers thereof. There are various feasible technologies available for automation, replacing conventional technologies and proposing new operation Methodology. Moreover, stakeholders need industries to be well aware of existing technologies; feel their responsibility towards environment and practices followed should be environment friendly and concentrated towards betterment of society. The main reasons for the industries to be responsible has many advantages: product supervision; standardization due to regulations and competitive national environment with public holding in international market.

Various researchers explicate GM as a manufacturing process but it is an integrated process in collaboration with conventional manufacturing with environmental protection. It's a conventional process with green practices implementing technologies to flourish up new domain and protecting inhabitances directly or indirectly involved with improvement in sustainability. With increase in sustainability, industry can enhance their performance indices and increases their productivity. In general; conventional business approach leads to emissions; disposed materials; industrial pollution involving congestion and unhygienic activities in handling materials. GM also considered as innovative thinking inculcated in conventional manufacturing with meaningful operations like designing of products; resource center handling and stock sharing and life science engineering management. GM influences supply chain and increases performance indices, therefore, need to conduct a detailed study on GM implementation issues in the Small and Medium Scale Industries in Indian context in order to develop an indigenous strategic synergetic effect, considering keyaspects of Regulatory Norms and Environmental Responsibilities for the manufacturing industry

\section{REFERENCES}

[1] Abhijeet K. Digalwar, Ashok R. Tagalpallewar and Vivek K Sunnapwar, "Green manufacturing performance measures: an empirical investigation from Indian manufacturing industries," Measuring Business Excellence, Vol. 17, No. 4, pp. 59-75, 2013.

[2] C. Adams and A. Neely, "The performance prism to boost MandA success," Measuring Business Excellence, Vol. 4, No. 3, pp. 19-23, 2000.

[3] S. Ayuso, M.A. Rodrguez and J.E. Ricart, "Responsible competitiveness at the micro level of the firm using stakeholder dialogue as a source for new ideas: a dynamic capability underlying sustainable innovation," Corporate Governance, Vol. 6, No. 4, pp. 475-490, 2006.

[4] G. Azzone and G. Noci, "Identifying effective PMSs for the deployment of 'green' manufacturing strategies," International Journal of Operations and Production Management, Vol. 18, No. 4, pp. 308-335, 1998.

[5] M.A. Badri, D. Davis and D. Davis, "A study of measuring the critical factors of quality management," International Journal of Quality and Reliability Management, Vol. 12, No. 2, pp. 36-53, 1995.

[6] H. Beheshti, "Gaining and sustaining competitive advantage with activity based cost management system," Industrial Management and Data Systems, Vol. 104, No. 5, pp. 377-383, 2004.

[7] M. Berry and D. Rondinelli, "Proactive corporate environmental management: a new industrial reVolution," Academy of Management Executive, Vol. 12, No. 2, pp. 38-50, 1998.

[8] R. Bose, "Knowledge management metrics," Industrial Management and Data System, Vol. 104, No. 6, pp. 457-468, 2004.

[9] C.H. Daub and R. Ergenzinger, "Enabling sustainable management through a new multi-disciplinary concept of customer satisfaction," European Journal of Marketing, Vol. 39, No. 9/10, pp. 998-1012, 2005.

[10] A.K. Digalwar and B.A. Metri, "Performance measurement framework for world class manufacturing," International Journal of Applied Management and Technology, Vol. 3, No. 2, pp. 83-102, 2005.

[11] A.K. Digalwar and K.S. Sangwan, "Development and validation of performance measures for world class manufacturing practices in India," Journal of Advanced Manufacturing Systems, Vol. 6 No. 1, pp. 21-38, 2007.

[12] A.K. Digalwar and K.S. Sangwan, "An overview of existing performance measurement frameworks in the context of world class manufacturing performance measurement," International Journal of Services and Operations Management, Vol. 9, No. 1, pp. 60-82, 2011.

[13] A.K. Digalwar, and K.S. Sangwan, "Role of knowledge management in world class manufacturing: an empirical investigation," The IEEE International Conference on Industrial Engineering and Engineering Management (IEEM-2011), Singapore, 6-9 December, pp. 415-419, 2011. 
[14] M. Gosselin, "An empirical study of performance measurement in manufacturing firms," International Journal of Production and Performance Management, Vol. 54, No. 5/6, pp. 419-437, 2005.

[15] A. Gunasekaran, C. Patel and R.E. McGaughy, "A framework for supply chain performance measurement," International Journal of Production Economics, Vol. 87, pp. 333-347, 2004.

[16] J. Haddock, "Consumer influence on internet-based corporate communication of environmental activities: the UK food sector," British Food Journal, Vol. 107, No. 10, pp. 792-805, 2005.

[17] J. Hair, R. Anderson, R. Tatham and W. Black, Multivariate Data Analysis, 4th ed., Prentice Hall, Englewood Cliffs, NJ, 1995.

[18] K. Hersey, "A close look at ISO14000: improving environmental safety," Professional Safety, Vol. 43, No. 7, pp. 26-29, 1998.

[19] A.A. Hervani, M.M. Helms and J. Sarkis, "Performance measurement for green supply chain management," Benchmarking: An International Journal, Vol. 17, No. 4, pp. 330-353, 2005.

[20] M. Laroche, J. Bergeron and G.B. Forleo, "Targeting consumers who are willing to pay more for eco friendly products," Journal of Consumer Marketing, Vol. 18, No. 6, pp. 503-520, 2001.

[21] S.Y. Lee, "Drivers for the participation of small and medium-sized suppliers in green supply chain," Supply Chain Management: An International Journal, Vol. 13,No. 3, pp. 85-198, 2008.
[22] B. Lin, C. Jones and C. Hsieh, "Environmental practices and assessment: a process perspective," Industrial Management and Data Systems, Vol. 101, No. 2, pp. 71-80, 2001.

[23] C. Lin, and S.M. Tseng, "The implementation gaps for the knowledge management system" Industrial Management and Data System, Vol. 106, No. 2, pp. 208-222, 2006.

[24] M. Litwin, How to Measure Survey Reliability and Validity, Sage Publications, Newbury Park, CA, 1995.

[25] J. Liyanage, "Operations and maintenance performance in production and manufacturing assets the sustainability perspective," Journal of Manufacturing Technology Management, Vol. 18, No. 3, pp. 304314, 2007.

[26] C.N. Madu, C. Kuei and I.E. Madu, "A hierarchic metric approach for integration of green issues in manufacturing: a paper recycling application," Journal of Environmental Management, Vol. 64, No. 3, pp. 261-272, 2002.

[27] Ministry of Environment and Forest (MOEF), India, 2010. [Online] Available at: http://envfor.nic.in/ (accessed January, 2015).

[28] R.P. Mohanty and S.G. Deshmukh, "Managing green productivity: some strategic directions," Production Planning and Control, Vol. 9, No. 7, pp. 624-633, 1998. 